ORIGINAL ARTICLE

\title{
A survey of flexibility training protocols and hamstring strains in professional football clubs in England
}

\author{
B Dadebo, J White, K P George
}

Br J Sports Med 2004;38:388-394. doi: 10.1135/bjsm.2002.000044

See end of article for authors' affiliations

Correspondence to:

Dr Dadebo, Department of

Exercise and Sport

Sciences, Manchester

Metropolitan University,

Crewe and Alsager

Faculty, Hassal Road,

Alsager ST7 2HL, UK.

b.dadebo@mmu.ac.uk

Accepted 27 March 2003
Objectives: To investigate the relation between current flexibility training protocols, including stretching, and hamstring strain rates (HSRs) in English professional football clubs.

Method: Questionnaire based data on flexibility training methods and HSRs were collected from 30 English professional football clubs in the four divisions during the 1998/99 season. Data were coded and analysed using cross tabulation, correlation, and multiple regression.

Results: Flexibility training protocols were characterised by wide variability, with static stretching the most popular stretching technique used. Hamstring strains represented $11 \%$ of all injuries and one third of all muscle strains. About $14 \%$ of hamstring strains were reinjuries. HSRs were highest in the Premiership (13.3 (9.4)/1000 hours) with the lowest rates in Division 2 (7.8 (2.9)/1000 hours); values are mean (SD). Most (97\%) hamstring strains were grade I and II, two thirds of which occurred late during training/matches. Forwards were injured most often. Use of the standard stretching protocol (SSP) was the only factor significantly related to $\mathrm{HSR}(r=-0.45, \mathrm{p}=0.031)$ in the correlation analysis, suggesting that the more $\mathrm{SSP}$ is used, the lower the HSR. About $80 \%$ of HSR variability was accounted for by stretching holding time (SHT), SSP, and stretching technique (STE) in the multiple regression equation: HSR $=37.79-10.33 \mathrm{SHT}$ $-10.05 S S P+2.24 S T E) \pm 2.34$. SHT (negatively correlated with HSR) was the single highest predictor, and accounted for $30 \%$ of HSR variability, and an additional $40 \%$ in combination with SSP.

Conclusions: Flexibility training protocols in the professional clubs were variable and appeared to depend on staffing expertise. Hamstring stretching was the most important training factor associated with HSR. The use of SSP, STE, and SHT are probably involved in a complex synergism which may reduce hamstring strains. Modification of current training patterns, especially stretching protocols, may reduce HSRs in professional footballers.
M uscle strains are common in sport and represent $41 \%$ of all injuries reported in the English professional football clubs. ${ }^{1}$ Of all the muscle strains associated with competitive sport, hamstring strains are the most common and problematic. ${ }^{2-4}$ Hamstring strain was reported to be the most common injury in Australian Rules Football, accounting for $13 \%$ of injuries, and is responsible for the most time missed after injury. ${ }^{5}$ The peculiar characteristics of the hamstring muscles-biathrodial, made predominantly of type II fibres ${ }^{6}$, and containing less titin protein ${ }^{8}$ - may put the muscle group at higher risk of strains. Hamstring strains are often difficult and slow to rehabilitate, and the problem is compounded by the high hamstring reinjury rate.

The causes of hamstring strain are complicated and multifactorial, $^{10}$ involving muscle strength imbalance, ${ }^{11} 12$ inadequate warm up, ${ }^{13}{ }^{14}$ lack of flexibility, ${ }^{15}$ muscle fatigue, ${ }^{13} 17$ and previous strain/inadequate rehabilitation. ${ }^{5}{ }^{18}$ Extremes of flexibility have been associated with injury, ${ }^{19} 20$ and one specific area of attention is the impact of suboptimal flexibility on hamstring injury. The role of stretching in enhancing flexibility and reducing injury remains contentious. $^{21} 22$ Methodological inconsistencies as well as varied subject populations and research designs have often limited such research. In fact, most studies that have indicated a relation between stretching and injury were retrospective, with questionable exposure $e^{23-25}$ and in some cases no statistical tests performed. ${ }^{15}$ Other studies have found no relation between flexibility training and injury. ${ }^{18}{ }^{26}$

On the other hand, inappropriate stretching interacting with other factors has been suggested to be partially responsible for injury. ${ }^{27}$ This is supported by the fact that studies that showed a positive relation between stretching and injury were those that used multiple interventions. ${ }^{10}{ }^{21}$ As a consequence of such data, guidelines for stretching and flexibility training have been proposed, including the concept of three to five stretching sessions a week, ${ }^{28}$ with four to five repetitions ${ }^{29}$ per hamstring muscle group and a holding time of 15-30 seconds. These approaches significantly increased flexibility with only minimal additional benefits when holding times were extended for $1-2$ minutes. ${ }^{3031}$ The choice of the ideal stretching techniques to achieve such increases in flexibility and potentially reduce injury is contentious. Static stretching has been advocated in combination with proprioceptive neuromuscular facilitation (PNF), whereas ballistic stretching is considered potentially dangerous. ${ }^{28}$ In addition, optimal fitness and strength training including eccentric hamstring strength training have been advocated, ${ }^{41833}$ as well as stretching with the anterior pelvic tilt position. ${ }^{34}$

Given the contentious nature of research that has assessed the link between hamstring flexibility and injury and the broad range of stretching techniques and strategies advocated in the scientific and popular literature, it is somewhat surprising that there is a relative lack of literature on stretching and flexibility training that occurs in professional sport. Few studies have reported the kind of flexibility training used by athletes in general, and little or no descriptive research exists on the possible link between

Abbreviations: HSF, hamstring stretching frequency or repetitions per session; HSR, hamstring strain rates; PNF, proprioceptive neuromuscular facilitation; SHT, static stretching holding time; SSP, standard stretching protocol; STE, stretching technique employed 
flexibility training protocols and injury rates in professional footballers. The purpose of this study therefore was to determine the current protocols of flexibility training, including stretching protocols, in the English professional football clubs and whether any relation exists with hamstring strain rates (HSRs).

\section{METHODS}

This study was conducted as a follow up to one involving 30 professional football clubs. ${ }^{35}$ However, only 20 of the original clubs responded, hence a further 16 clubs selected randomly from all four divisions were invited to participate. Of these, 10 clubs responded. In all, 30 out of 46 clubs took part in this study, eight from the Premiership, 10 from Division 1, and six each from Divisions 2 and 3. Team doctors, physiotherapists, managers/coaches, and fitness trainers who work with the first teams of their respective clubs provided information based on the 1998/99 soccer season. Self administered questionnaires with a mixture of open ended and closed questions were mailed to staff of clubs who agreed to participate in the study. The questionnaire was designed with the help of the Division of Public Health Medicine and Epidemiology (University of Nottingham), and was based on a review of the relevant literature in the area of study. The questionnaire contained clear definitions of words such as injury and reinjury, and classification of hamstring strains, etc to facilitate completion. It also provided guidelines for completion of specific sections by the most appropriate support staff.

Pertinent areas of interest in relation to the study included: staffing complement, demands of the football year, fitness training procedures, warm up and warm down procedures, flexibility training procedures, and injury information. In this study, injury refers to "a physical impairment received during a competitive match or training session which prevented a player from being available for selection for the next competitive game ${ }^{\prime \prime}{ }^{36}$ Hamstring reinjury in this survey refers to a second injury occurring at the same site during the 1998/ 99 football season. Hamstring strains were classified as grade I (minor injury with normal, but painful contraction), II (moderate, partial tear with abnormal contraction), and III (complete tear with weak to non-existent contraction) ${ }^{33}{ }^{34}$ and diagnosed by the team doctors. Clubs that took part in this survey used on average two doctors working full time or part time. About $45 \%$ of these doctors have MSc/Diploma Sports Medicine qualification, the others being orthopaedic surgeons $(14 \%)$, general practitioners $(17 \%)$, and osteopaths $(24 \%)$. On average, the head doctor of the clubs had experience in sports medicine ranging from 6.5 years (Division 3) to 9.8 years (Premiership). The timing of hamstring strain incidence was also noted as early, mid, and late onset during the first, middle, or last third of matches or training sessions respectively. In this survey certain terms were coded for simplicity, SSP (standard stretching protocol), STE (stretching technique employed), SHT (static stretching holding time), and HSF (hamstring stretching frequency or repetitions per session). STE referred to static, PNF, or ballistic stretching. In static stretching, the muscle is moved slowly through its range of motion and held for a length of time, whereas ballistic involves jerky/bouncing movements rapidly taking the muscle through its range of motion. PNF $^{39}$ referred to partner assisted slow movement of the muscle through its range of motion with a concomitant combination of alternating contraction and reflex relaxation of both agonist and antagonist groups. SSP in this survey referred to the use of either the static or PNF stretching technique, preceded by a warm up session, and holding the static stretch for 15-30 seconds. Accordingly flexibility training protocols in the survey implies stretching exercises used for the purposes of enhancing flexibility of the hamstring muscles together with warm up and warm down activities.

Supervision of flexibility training was the responsibility of the sports scientists and fitness trainers with support from coaches and physiotherapists. However, as sports scientists and fitness trainers were employed mainly by the Premiership clubs, the head physiotherapists and coaches in the lower divisions often led and supervised flexibility training. The minimum average experience of the head physiotherapists was 9.8 years. Over $90 \%$ of full time physiotherapists employed have chartered and/or FA Diploma in Physiotherapy as qualification.

The proposed questionnaire was piloted with three English professional clubs, with doctors, physiotherapists, and coaches who had experience working with first teams as respondents. These three clubs did not take part in the final study, although appropriate amendments were made to obtain the final questionnaire based on the responses and comments received. The clubs that agreed to participate in the main study were mailed questionnaires with self addressed, stamped envelopes. Clubs were assured of the confidentiality with which responses would be treated. Reminders were sent to 23 clubs who did not respond within two weeks, and new questionnaires were sent together with the second reminders to non-responding clubs within four weeks. Follow up phone calls were used to facilitate completion and return of questionnaires. Of the 16 clubs that did not take part, two indicated that it was against their policy to participate in such studies, and the other 14 could not do so because they were too busy at the time. Partial completion of questionnaires, particularly section 6 (injury information) by 11 clubs, was also attributed to the difficulty in retrieving records or the fact that the records were simply not available.

Total muscle and hamstring strain rates were calculated from information contained in the returned questionnaires based on the total number of matches (each match lasting 90 minutes) and training sessions (each session lasting 120 minutes) completed during the season. The total number of muscle and hamstring strains reported was divided by the total time of exposure to match playing and training during the season and expressed per 1000 hours. The data were screened for variance of individual data, including tests for skewness and kurtosis. Four reports on frequency of hamstring stretching from three Division 1 clubs and one Division 3 club were considered outliers and excluded from the analysis. The distribution of hamstring strains, muscle strains, and total injuries were cross tabulated, and the relation with training practices assessed using Pearson's (interval data) or Spearman's rank order (nominal data) correlation and then stepwise multiple regression. One-way analysis of variance was used to determine the main and interaction effects of stretching factors on HSR after the tests of association. $p<0.05$ was considered significant (SPSS).

\section{RESULTS}

Thirty clubs returned the study questionnaires, which consisted of six sections; however, only 19 clubs completed all six sections. Section 6 of the questionnaire had a series of questions on injury information, the completion of which required retrieving stored information. Therefore the ability to complete this section depended on record keeping and storage of information. Thus section 6 was the least fully completed section, with 23 respondents. Although seven clubs failed to complete section 6 fully, the total number of responses about the incidence of hamstring strains for example was 27. Overall, the total number of responses declined for questions that demanded details of 
Table 1 Staffing complement employed by professional football clubs in England

\begin{tabular}{lllll}
\hline & Premiership (N=8) & Division $\mathbf{1}(\mathbf{N}=10)$ & Division 2 (N=6) & Division 3 (N=6) \\
\hline Doctors & $2(1-5)$ & $1(1-3)$ & $1(1-4)$ & $1(1-4)$ \\
Physiotherapists & $2(2-7)$ & $2(1-3)$ & $2(1-3)$ & $2(1-2)$ \\
Fitness trainers & $1(0-2)$ & $0(0-1)$ & $1(0-2)$ & $0(0-3)$ \\
Sports scientists & $1(1-3)$ & $0(0-1)$ & $0(0-1)$ & $0(0)$ \\
Football players & $35(31-37)$ & $28(22-40)$ & $20(20-35)$ & $20(20-26)$ \\
\hline
\end{tabular}

distribution/timing of hamstring strains or subclassification of specific training programmes. This led to differential totals included in the respective analyses conducted: 21 responses for flexibility training compared with 27 for hamstring strains or 30 for number of physiotherapists employed. Again, although the number of responses about hamstring strains was 27, data on hamstring strain rates/1000 hours could only be calculated for 23 clubs because some clubs failed to provide information on their training duration.

\section{Staffing complement}

Clubs in the Premiership employed more support staff than all other divisions (table 1). Most Premiership clubs employed at least two doctors compared with one for all other divisions. Most clubs in all divisions employed at least two physiotherapists, with the widest range in the Premiership. $^{2-7}$ Sports scientists and fitness trainers were only sporadically employed, with at least one sports scientist exclusively employed in the Premiership (table 1). The number of players employed in the professional football league increased from Division 2 and 3 clubs to a maximum in the Premiership, which probably accounted for the additional support staff needed.

\section{Training patterns}

The training modalities used by the professional clubs included endurance training, strength/resistance training, and flexibility training. The training patterns were characterised by very wide inter/intradivision variability (table 2 ). The pattern of training modalities could not be reported by some of the clubs (table 2), explaining the differences in response numbers. However, on average, clubs in Divisions 1 and 2 seemed to devote more time per week to endurance training, whereas the Premiership clubs devoted slightly less time, and Division 3 clubs devoted the least time.

Strength/resistance training was also characterised by wide inter/intradivision variability, although half of Division 2 and 3 clubs failed to report, and two Premiership clubs and one Division 1 club also failed to report. The Premiership spent more time on strength/resistance training, whereas only about half this time was devoted by Division 3 clubs, with clubs in Division 1 and 2 spending about two thirds of this time on strength/resistance training.

Unlike with endurance and strength/resistance training where some responses were similar, flexibility training exhibited distinct patterns for each division. The most time spent on flexibility training per week was by Division 1 clubs, followed by the Premiership clubs, then Division 2, and the least by Division 3. This pattern in flexibility training was similar to the trend in total training times for all three modalities.

The Premiership clubs devoted almost $40 \%$ of total training time to flexibility training, with about $30 \%$ on endurance and $30 \%$ on strength/resistance training. Division 3 clubs also exhibited similar training protocol distributions. In Division 1, nearly $50 \%$ of training time was devoted to flexibility training, with about $30 \%$ and $20 \%$ to endurance and strength/ resistance training respectively. Division 2 clubs used the least flexibility training, representing a third of total training time a week, while almost $40 \%$ of time was used for endurance training.

\section{Warm up and warm down procedures}

All clubs reported using warm up protocols before training sessions and matches. Table 3 summarises the characteristics of warm up and warm down protocols. Whereas almost two thirds of all clubs used mainly active warm up, over two thirds of Division 2 clubs used both active and passive warm up protocols. In addition, five out of six Division 2 clubs and seven out of 10 Division 1 clubs reported using warm down protocols both after training and after matches. In the Premiership and Division 3 clubs, the use of warm down protocols after a match fell to half (four out of eight Premiership clubs) and a third (two out of six Division 3 clubs) respectively compared with its use after training. There were no differences in the duration of warm up use across all divisions, with warm ups lasting 22-25 minutes, although Division 2 clubs spent less time on warm down compared with the other divisions. Overall Division 3 clubs used warm down protocols the least, and Division 2 clubs the most. Stretching before warm up was not popular in all divisions except Division 2 where half (three out of six) used stretching before warming up. However, seven out of eight Premiership clubs stretched both during and after warm up, with seven out of 10 Division 1 and four out of six Division 3 clubs doing likewise.

\section{Hamstring stretching}

Static stretching was reported as the most popular stretching technique used among all clubs in this study. In most cases,

Table 2 Distribution of weekly training in professional football clubs

\begin{tabular}{lllll}
\hline Training modality & Premiership $(\mathbb{N}=8)$ & Division $1(\mathbb{N}=10)$ & Division $2(\mathbb{N}=6)$ & Division $3(\mathbb{N}=6)$ \\
\hline Endurance & $605(516)(n=5)$ & $678(439)(n=9)$ & $654(373)(n=5)$ & $352(289)(n=3)$ \\
Strength/resistance & $614(172)(n=7)$ & $403(204)(n=9)$ & $440(165)(n=3)$ & $317(274)(n=3)$ \\
Flexibility & $735(458)(n=7)$ & $978(1084)(n=8)$ & $537(234)(n=3)$ & $421(239)(n=3)$ \\
Total & $1954(814)(n=5)$ & $2058(1134)(n=8)$ & $1631(202)(n=3)$ & $1090(529)(n=3)$ \\
Proportion of flexibility & 37.6 & 47.5 & 32.9 & 38.6 \\
training (\%) & & & &
\end{tabular}

Values are mean (SD) (minutes/week). N represents the number of clubs in a particular division participating in the study. $n$ represents the number of clubs that responded to a particular mode of training. 
Table 3 Characteristics of warm up and warm down procedures used by the professional football clubs

\begin{tabular}{|c|c|c|c|c|}
\hline Characteristic & $\begin{array}{l}\text { Premiership } \\
(\mathrm{N}=8)\end{array}$ & $\begin{array}{l}\text { Division } 1 \\
(\mathrm{~N}=10)\end{array}$ & $\begin{array}{l}\text { Division } 2 \\
(\mathrm{~N}=6)\end{array}$ & $\begin{array}{l}\text { Division } 3 \\
(\mathrm{~N}=6)\end{array}$ \\
\hline Active* & 5 & 6 & 2 & 4 \\
\hline Passive† & 1 & 0 & 0 & 0 \\
\hline Active and passive & 2 & 4 & 4 & 2 \\
\hline Stretching before warm up & 1 & 3 & 3 & 2 \\
\hline Stretching during/after warm up & 7 & 7 & 3 & 4 \\
\hline Duration of warm up (minutes) & $23.1(4.4)$ & $24.9(8.3)$ & $22.5(4.2)$ & $25.8(4.1)$ \\
\hline Duration of warm down (minutes) & $17.2(11.5)$ & $14.4(12.7)$ & $10.1(3.6)$ & $14.6(3.7)$ \\
\hline $\begin{array}{l}\text { Regular use of warm down protocol } \\
\text { (after training) }\end{array}$ & 6 & 7 & 5 & 3 \\
\hline $\begin{array}{l}\text { Regular use of warm down protocol } \\
\text { (after match) }\end{array}$ & 4 & 7 & 5 & 2 \\
\hline \multicolumn{5}{|c|}{$\begin{array}{l}\text { Where applicable, values are mean (SD). } \\
\text { *Active warm up involves gaining body temperature through one's own physical activity. †Passive warm up } \\
\text { involves gaining body temperature through the use of an external heat source (application of hot material or use of } \\
\text { additional clothing to retain heat). }\end{array}$} \\
\hline
\end{tabular}

static stretching was used in combination with PNF stretching (table 4). Most clubs in all divisions used an SSP. However, Division 2 (four out of six) appear to have a lower tendency to adhere to the protocol at all/most sessions whereas all Premiership and Division 1 and Division 3 (five out of six) clubs adhered more strictly to stretching protocols. Hamstring SHTs exhibited wide variability, with the least in Division 3 clubs. The longest SHT reported was about 30 seconds by the Premiership clubs, whereas players in Division 3 clubs stretched for only about half this time, with Division 1 and 2 clubs holding stretches for about 20 seconds. Players in the Premiership and Division 2 on average stretched with fewer repetitions per session than those in Divisions 1 and 3. These reports on HSF exclude reports from three Division 1 clubs and one Division 3 club which reported HSFs of 10, 17, 20, and 25, which were considered unrealistic, hence outliers.

\section{Distribution of muscle and hamstring strains}

During the 1998/99 football season, a total of 1435 injuries were recorded in all 30 clubs that took part in the study, of which 479 were muscle strains and 158 hamstring strains. Hamstring strains thus represented $11 \%$ of all injuries and muscle strains $33 \%$. Overall the highest total number of injury and muscle strains were in Division 3 closely followed by the Premiership and Divisions 1 and 2 (table 5). However, HSRs were highest in the Premiership, followed by Divisions 3,1 , and 2 respectively.

Out of the 158 hamstring strains recorded, 156 were classified into grades; 151 were of grade I and II severity, and about $14 \%$ of these were reinjuries. The Premiership recorded the highest numbers of both grade II and III injuries (27 and 3 respectively) compared with 13 and 0 respectively for Division 2, while Divisions 1 and 3 recorded 25 and 1, and 9 and 1 respectively. In the Premiership, four out of 46 hamstring strains were reinjuries, as were seven out of 56 in Division 1, three out of 23 in Division 2, and seven out of 33 in Division 3. Thus hamstring reinjury rates were lowest in the Premiership (9\%) and highest in Division $3(21 \%)$. Forwards had the highest risk, sustaining 49 out of 122 hamstring strains, whereas goalkeepers were at very low risk (three out of 122). Defenders (36 out of 122) and midfielders (34 out of 122) had similar risks. Thus, compared with goalkeepers, the incidence ratio of hamstring strain in the playing positions was 16:1 for forwards, 12:1 for defenders, and 11:1 for midfielders. About two thirds of hamstring strains occurred during matches (77 of 122) compared with training (45 of 122). Similarly two thirds occurred late during activity, whether training ( 25 of 45$)$ or in a match (49 of 77). The numbers of strains occurring early in and midway through training were the same (10 of 45 ), whereas the corresponding numbers in matches were 12 and 16 out of 77 . Almost all hamstring strains were managed conservatively, with only $1.6 \%$ (three of 158 ) being managed surgically.

\section{HSRs and training factors}

The use of an SSP was the only training factor that correlated significantly and negatively with HSR $(r=-0.53, \mathrm{p}=0.01$; table 6), suggesting that the use of SSPs is associated with lower HSR.

Table 4 Characteristics of hamstring stretching in the professional football clubs

\begin{tabular}{lllll}
\hline & $\begin{array}{l}\text { Premiership } \\
(\mathbf{N}=8)\end{array}$ & $\begin{array}{l}\text { Division } \mathbf{1} \\
(\mathbf{N}=10)\end{array}$ & $\begin{array}{l}\text { Division 2 } \\
(\mathbf{N}=6)\end{array}$ & $\begin{array}{l}\text { Division 3 } \\
(\mathbf{N}=6)\end{array}$ \\
\hline $\begin{array}{l}\text { Use of SSP } \\
\text { Number of clubs strictly adhering to }\end{array}$ & 6 & 9 & 5 & 4 \\
SSP at most/all sessions & $6(n=6)$ & $9(n=9)$ & $4(n=6)$ & $4(n=5)$ \\
SHT (s) & $31.3(14.6)$ & $23.0(7.90)$ & $21.7(11.3)$ & $13.3(5.0)$ \\
HSF per sessiont & $3(2-5)(n=7)$ & $5(2-10)(n=6)$ & $3(2-6)(n=5)$ & $\begin{array}{l}5(3-6)(n=4) \\
8: 1: 1\end{array}$ \\
$\begin{array}{l}\text { Proportions of STE } \\
\text { (static:PNF:ballistic) }\end{array}$ & $5: 1: 1$ & $6: 1: 2$ & & $8: 1: 1$ \\
\hline
\end{tabular}

$\mathrm{N}$ represents the number of clubs in a particular division participating in the study.

$\mathrm{n}$ represents the number of clubs that responded to the questionnaire on the stated component of stretching *Values are mean (SD).

†Values are mean (range).

HSF, hamstring stretching frequency or repetitions per session; PNF, proprioceptive neuromuscular facilitation; SHT, static stretching holding time; SSP, standard stretching protocol; STE, stretching technique employed. 
Table 5 Distribution of injury rates in the professional football clubs

\begin{tabular}{|c|c|c|c|c|c|}
\hline & Premiership $(\mathrm{N}=8)$ & Division $1(N=10)$ & Division $2(\mathrm{~N}=6)$ & Division $3(\mathrm{~N}=6)$ & All divisions $(\mathrm{N}=30)$ \\
\hline & $\begin{array}{l}13.3(4.1 \text { to } 22.5) \\
(n=4)\end{array}$ & $\begin{array}{l}9.3(6.4 \text { to } 10.6) \\
(n=10)\end{array}$ & $\begin{array}{l}7.8(5.0 \text { to } 10.6) \\
(n=4)\end{array}$ & $\begin{array}{l}10.1(5.9 \text { to } 14.3) \\
(n=5)\end{array}$ & $\begin{array}{l}9.9(7.7 \text { to } 12.1) \\
(n=23)\end{array}$ \\
\hline MSR/1000 hours & $\begin{array}{l}36.8(9.4 \text { to } 64.2) \\
(n=4)\end{array}$ & $\begin{array}{l}29.3(23.3 \text { to } 34.8) \\
(n=10)\end{array}$ & $\begin{array}{l}26.5(7.1 \text { to } 45.9) \\
(n=3)\end{array}$ & $\begin{array}{l}42.7(39.9 \text { to } 45.5) \\
(n=5)\end{array}$ & $\begin{array}{l}33.3(24.9 \text { to } 41.7) \\
(n=22)\end{array}$ \\
\hline TIR/1000 hours & $\begin{array}{l}127.0(47.3 \text { to } 206.7) \\
(n=4)\end{array}$ & $\begin{array}{l}87.1(62.8 \text { to } 111.4) \\
(n=10)\end{array}$ & $\begin{array}{l}84.3(75.4 \text { to } 93.2) \\
(n=3)\end{array}$ & $\begin{array}{l}132.6(47.3 \text { to } 217.9) \\
(n=5)\end{array}$ & $\begin{array}{l}104.3(78.2 \text { to } 130.4) \\
(n=22)\end{array}$ \\
\hline
\end{tabular}

$95 \%$ confidence intervals are shown in parentheses. $\mathrm{N}$ represents the number of clubs in a particular division participating in the study. $\mathrm{n}$ represents the number of clubs that responded to the questionnaire on the stated component of injury.

HSR, Hamstring strain rate; MSR, muscle strain rate; TIR, total injury rate.

In addition, there was a significant interactive effect between SHT and STE (analysis of variance; $F=7.1, \mathrm{p}=$ 0.04 ) without significant individual main effects (SHT: $F=$ $2.8, \mathrm{p}=0.71$; STE: $F=1.7, \mathrm{p}=0.3$ ) (table 7).

\section{Prediction of HSR}

Stepwise multiple regression analysis using the specific training factors as independent variables indicated that stretching was the most important factor associated with HSR (table 8). SHT was the single most important predictor, accounting for nearly $30 \%$ of variability of HSR $\left(r^{2}=0.29\right)$. SSP in combination with SHT adds $40 \%$ to the variability of HSR $\left(r^{2}=0.69\right)$. Almost $80 \%$ of the variability of HSR was accounted for by three independent variables, SHT, the use of SSP, and STE (table 8). The multiple regression equation of hamstring strain is:

$$
\mathrm{HSR}=37.79-(0.33 \mathrm{SHT}+10.05 \mathrm{SSP}+2.24 \mathrm{STE}) \pm 2.34
$$

\section{DISCUSSION}

The flexibility training protocols of 30 English professional football clubs during the 1998/99 season were studied, with the aim of identifying any training factors that may be associated with HSR. There were no differences in training protocols within or between divisions that could be attributed to the fact that people of different backgrounds and experience are recruited to manage and supervise training. Moreover, the desired impact of sports scientists/fitness trainers is probably not being achieved because of the low numbers involved in professional football in England. Furthermore, there are no clear guidelines on the number and qualifications of staff to be employed by clubs. ${ }^{40}$ Appropriate stretching protocols are thought to increase flexibility, but the optimum level of flexibility to prevent injury is not clear and may vary between muscle groups and probably sports. There is the general perception that the concept of specific training according to individual needs is familiar to coaches/trainers and players. Consequently it has generally been assumed that coaches/trainers and players know how to prepare in terms of stretching and flexibility training. ${ }^{41}$

This study shows that hamstring SHT, the use of SSPs, and the type of STE were the most important training factors affecting HSR. As most clubs used and adhered to SSPs, it could be argued that it is what the players actually do in practice, particularly the STE and SHT, that determines how much benefit is obtained in terms of prevention of HSRs. What is apparent is that the stretching protocols currently used by professional footballers are not necessarily detrimental, but may only be beneficial when the STEs and SHTs are appropriate. We found no significantly different HSRs among the divisions. This may be because the numbers were too small or the stretching protocols used by the clubs were similar and not sufficient to promote the desired benefits. Current recommendations are a combination of static and PNF techniques instead of ballistic stretching ${ }^{28}$; an SHT of
Table 6 Correlation of specific training factors with hamstring strain rate in professional football clubs

\begin{tabular}{llll}
\hline Factor & $\boldsymbol{r} / \boldsymbol{\rho}$ Value & $\mathbf{p ~ V a l u e ~}$ & $\mathbf{N}$ \\
\hline Use of SSP & $\rho=-0.53$ & 0.01 & 23 \\
HSF & $r=-0.13$ & 0.57 & 22 \\
STE & $\rho=-0.15$ & 0.51 & 23 \\
SHT & $r=0.02$ & 0.94 & 23 \\
SRT (min/week) & $r=0.34$ & 0.18 & 22 \\
Flexibility training (min/week) & $r=0.06$ & 0.84 & 21 \\
Endurance training (min/week) & $r=-0.31$ & 0.22 & 22 \\
Use of warm down after training & $\rho=-0.21$ & 0.35 & 23 \\
Use of warm down after matches & $\rho=-0.03$ & 0.88 & 23 \\
\hline
\end{tabular}

$\mathrm{N}$, Number of responses; SSP, standard stretching protocol; HSF, hamstring stretching frequency; STE, stretching technique employed; SHT, stretching holding time; SRT, strength/resistance training.

Table 7 Additive model for interaction effect of training factors and hamstring strain rate

\begin{tabular}{llllll}
\hline \multicolumn{2}{c}{$\begin{array}{l}\text { Type III sum of } \\
\text { squares }\end{array}$} & df & $\begin{array}{l}\text { Mean } \\
\text { square }\end{array}$ & $\boldsymbol{F}$ & p Value \\
\hline Corrected model & $578.743^{*}$ & 17 & 34.044 & 3.044 & 0.142 \\
Intercept & 1509.665 & 1 & 1509.665 & 136.588 & 0.000 \\
HSF & 8.171 & 2 & 4.085 & 0.370 & 0.712 \\
SHT & 92.945 & 3 & 30.982 & 2.803 & 0.712 \\
STE & 56.482 & 3 & 18.827 & 1.703 & 0.303 \\
HSF $\times$ SHT & 0.000 & 0 & & & \\
HSF $\times$ STE & 0.000 & 0 & & & \\
SHT $\times$ STE & 235.756 & 3 & 78.585 & 7.110 & 0.044 \\
HSF $\times$ SHT $\times$ STE & 0.000 & 0 & & & \\
Error & 44.211 & 4 & 11.053 & & \\
Total & 2692.283 & 22 & & & \\
Corrected total & 622.954 & 21 & & & \\
\hline
\end{tabular}

Analysis of variance; dependent variable hamstring strain rate. ${ }^{*} R^{2}=0.929$ (adjusted $R^{2}=0.627$ ).

HSF, Hamstring stretching frequency (repetitions per session); SHT, hamstring stretching holding time; STE, stretching technique employed.

Table 8 Model summary for multiple regression for hamstring strain rate

\begin{tabular}{llll}
\hline $\begin{array}{l}\text { Model variables } \\
\text { included }\end{array}$ & $\boldsymbol{R}$ & $\boldsymbol{R}^{2}$ & SE Est \\
\hline 1 & 0.54 & 0.29 & 3.97 \\
2 & 0.83 & 0.69 & 2.74 \\
3 & 0.89 & 0.79 & 2.34 \\
\hline
\end{tabular}

The model components include: 1, One predictor: (constant), hamstring stretching holding time (SHT) (seconds); 2, two predictors: (constant), SHT (seconds) and use of standard stretching protocol (SSP); 3, three predictors: (constant), SHT (seconds), SSP, and stretching technique employed STE. (1) $\mathrm{SHT}$ indicates the extent to which the stretching holding time used influences the tendency for injury prevention; (2) SSP indicates the extent to which the use of standard stretching protocols used influences the tendency for injury prevention; (3) STE indicates which stretching techniques employed influence the tendency for injury prevention. 
15-30 seconds is also advocated..$^{30}$ Up to four repetitions per stretching session is thought to be adequate. ${ }^{29}$ In a more recent study, ${ }^{42} 15$ seconds holding time was found to be more effective in enhancing active flexibility but not passive flexibility compared with five seconds. These findings suggest that gains in flexibility may be linearly related to SHTs up to 30 seconds. In our study, but for the wide intra and inter division variability, SHTs would otherwise be within acceptable ranges. Consistency in the use of such SHTs in protocols using the sound techniques may hold the key for benefits of stretching in injury prevention. Arguments based on the basic scientific evidence that stretching could cause injury have been suggested, ${ }^{21}$ appear laudable, and have not been disputed. However, if investigations into stretching fail to consider consistent use of appropriate STEs and SHTs and their interaction with other training factors, the results are unlikely to reveal any relation with injury. Authors of such studies are likely to report conflicting findings, and this raises concern about experimental designs, whether randomised clinical trials or cohort, and their interpretations. ${ }^{22}$ In a previous review article, ${ }^{21}$ the only studies showing a link between HSR and stretching were those that used multiple intervention. In the present study, the simple relation between SHT and HSR could not be established by correlation analysis, but only by stepwise multiple regression analysis. Moreover SHT and STE showed no single main effects, but rather a significant interaction effect on HSR. This therefore implies that stretching is only beneficial if held for an optimal length of time-for example, 15-30 seconds-as suggested by the literature. These findings indicate that the causes of injury in general, and hamstring strains in particular, are likely to be complex, interactive, and multifactorial ${ }^{27}$ involving flexibility, strength, warm up, and fatigue. It has been suggested that stretching must therefore interact with other training factors to have an injury preventing effect. ${ }^{43}$ Our findings clearly suggest that the current stretching practices of professional footballers are not detrimental, and an improvement in the quality and consistency of use of more appropriate stretching may possibly further reduce HSR.

In this study, muscle and hamstring strains accounted for $33 \%$ and $11 \%$ of all injuries respectively. This compares with another study of four English professional football clubs, in which $41 \%$ of injuries were reported as muscle strains, ${ }^{1}$ and a study of Australian rules football, in which hamstring strains represented $13 \%$ of all injuries. ${ }^{5}$ Hamstring strains occur when strong concentric quadriceps contractions generate forces that the eccentric strength of the hamstrings cannot withstand. They are therefore prevalent in sports requiring sudden bursts of speed. ${ }^{44}{ }^{45}$ In the present study, forwards, who "take off" more often with sudden bursts of speed, had the highest relative risk (16:1) with respect to goalkeepers compared with defenders (12:1) and midfielders (11:1) Even though it has been reported that midfielders do more running and are thus more prone to injury, ${ }^{46}{ }^{47}$ the literature suggests that high instantaneous speed demands are associated with hamstring strains. Our study supports such a mechanism. In fact, it has been reported that hamstring strains are more common in faster athletes. ${ }^{18}$ In this survey, goalkeepers had the lowest HSRs. This can be explained by the relatively rare demand for sudden bursts of speed in this position rather than them having the greatest flexibility. Grade III hamstring strains were rare, and most of the few that occurred were in the Premiership. Tiredness has been suggested to contribute to hamstring strains. ${ }^{17}$ The fact that most hamstring strains in our study occurred late on during activity supports this. In all the 122 hamstring strains that were timed, 74 occurred late during the activity (training or matches), 26 occurred mid-activity, and the remaining 22 occurred during early activity.
Take home message

Stretching is probably involved in a complex, interactive, and multifactorial relation with hamstring strain. However, stretching may be beneficial only if the technique employed and the stretch holding times are adequate; the number of repetitions of a stretch may not be important. The flexibility training protocols currently used by the professional football clubs need to be reviewed to ensure consistency in the use of static stretching/PNF with a stretch holding time of 1530 seconds.

In this survey, reinjuries represented $14 \%$ of hamstring strains and appeared to increase the lower the division: from $9 \%$ in the Premiership to $21 \%$ in Division 3. In Australian Rules football, hamstring reinjuries have been reported as $34 \%$, more than double the average rate in all divisions of the football league in England. Apart from individual susceptibility, inadequate rehabilitation ${ }^{18} 45$ and premature return to competition have been mentioned as reasons for reinjury. This survey was a follow up to a previous study which investigated the use of physical profiling for guiding return to unrestricted training after injury, and 20 clubs out of the 30 in this survey took part in that study. ${ }^{35}$ It is therefore not surprising to note the relatively low rates of hamstring reinjury after the increased awareness in benchmarking to guide return to training after injury. Another reason could be the availability of sports scientists and physiotherapists who are responsible for rehabilitation of injured players. This survey shows that the number of physiotherapists and sports scientists decrease from the Premiership to the lower divisions, and this may explain the trend in hamstring reinjury rates.

The major limitation of this study is that not all clubs in the football league took part, which was further compounded by the failure of some clubs to complete certain sections of the questionnaire, particularly those dealing with injury types and classifications. This may simply mean that such fine details of injury information are not routinely recorded. Another limitation is that training protocols were investigated in clubs and not in individual players. A study of individual players and their training practices may produce more realistic results. Similarly, although hamstring strains and the various grades were clearly defined, diagnosis and classification could only be assumed to be correct, given the experience of doctors and physiotherapists employed by the football clubs. However, there may be slight disparities in diagnosis and classification. Despite these limitations, however, the study shows the contribution of stretching to hamstring strains in professional footballers in England, and a modification of current training protocols is suggested. Further research is needed to determine ideal stretching protocols, particularly the most appropriate techniques and holding times for the prevention of hamstring strains.

In conclusion, this study suggests a relation between flexibility training protocols in professional footballers in England and HSR, and that STE and SHT are the most important components of a standard protocol that may have potential for prevention of hamstring strains.

\section{Authors' affiliations}

B Dadebo, K P George, Department of Exercise and Sport Sciences, Manchester Metropolitan University, Crewe and Alsager Faculty, Hassal Road, Alsager ST7 2HL, UK

J White, University of Nottingham Centre for Sports Medicine, Orthopaedic and Accident Surgery, Queen's Medical Centre, Nottingham NG7 2UH, UK 


\section{REFERENCES}

1 Hawkins RD, Fuller CW. A prospective epidemiological study of injuries in four English professional football clubs. Br J Sports Med 1999;33:196-203.

2 Brubaker CE, James SL. Injuries to runners. J Sports Med 1974;2: 189-98.

3 Ekstrand J, Gillquist J. Soccer injuries and their mechanisms: a prospective study. Med Sci Sports Exerc 1983;15:267-70.

4 Garrett WE. Muscle strain injuries. Am J Sports Med 1996:24:S2-8.

5 Seward H, Orchard J, Hazard H, et al. (1993) Football injuries in Australia at elite level. Med J Aust 1993:298-301.

6 O'brien M. Functional anatomy and physiology of tendons. Clin Sports Med 1992;11:505.

7 Garrett WE Jr, Califf JC, Bassett FH. Biomechanical correlates of hamstring injuries. Am J Sports Med 1984;12:98.

8 Waterman-Storer CM. The cytoskeleton of skeletal muscle: is it affected by exercise? A brief review. Med Sci Sports Exerc 1991;23:1240-9.

9 Worrell TW. Factors associated with hamstring injuries: an approach to treatment and preventive measures. Sports Med 1994;17:338-45.

10 Gleim GW, McHugh MP. Flexibility and its effect on sports injury and performance. Sports Med 1997;24:189-99.

11 Burkett L. Conservative factors in hamstring strains. Med Sci Sports 1970;2:39-42.

12 Christensen C, Wiseman D. Strength: The common variable in hamstring strain. Athletic Training 1972;7:36-40.

13 Dormon P. A report on 140 hamstring injuries. Aust J Sports Med $1971 ; 4: 30-6$

14 Ekstrand J, Gillquist J, Moller M, et al. Incidence of soccer injuries and their relation to training and team success. Am J Sports Med 1983;11:63-7.

15 Liemohn W. Factors related to hamstring strains. J Sports Med Phys Fitness 1978;18:71-6

16 Worrell TW, Perrin DH, Gansneder BM, et al. Comparison of isokinetic strength and flexibility measures between hamstring injured and non-injured athletes. J Orthop Sports Phys Ther 1991;13:118-25.

17 Mair SD, Seaber AV, Glisson RR, et al. The role of fatigue in susceptibility to acute muscle strain injury. Am J Sports Med 1996;24:137-43

18 Jonhagen S, Nemeth G, Eriksson E. Hamstring injuries in sprinters: the role of concentric and eccentric hamstring muscle strength and flexibility. Am J Sports Med 1994;22:262-6

19 Jones BH, Cowan DN, Tomlinson JP, et al. Epidemiology of injuries associated with physical training among young men in the army. Med Sci Sports Exerc 1993;25:197-203.

20 Taimela S, Kujala UM, Osterman K. Intrinsic risk factors and athletic injuries. Sports Med 1990;9:205-15.

21 Shrier I. Stretching before exercise does not reduce the risk of local muscle injury: a critical review of the clinical and basic science literature. Clin J Sports Med 1999:9:221-7.

22 Shrier I. Stretching before exercise: evidence based approach. $\mathrm{Br} J$ Sports Med 2000;34:324-5

23 Kirby RL, Simms FC, Symington VJ, et al. Flexibility and musculoskeletal symptomatology in female gymnasts and age-matched controls. Am J Sports Med 1981;3:190-64

24 Clement DB, Taunton JE, Smart GW. Achilles tendinitis and paratendinitis: aetiology and treatment. Am J Sports Med 1984;12:179-84.
25 Reid DC, Burnham RS, Saboe LA, et al. Lower extremity flexibility patterns in classical ballet dancers and their correlation to lateral hip and knee injuries. Am J Sports Med 1987; 15:347-52.

26 Hannessey L, Watson AWS. Flexibility and posture assessment in relation to hamstring injury. Br J Sports Med 1993:27:243-6.

27 Worrel TW, Perrin DH. Hamstring muscle injury: The influence of strength, flexibility warm-up and fatigue. J Orthop Sports Phys Ther 1992;16:12-18.

28 Wallin D, Ekblom B, Grahn R, et al. Improvement of muscle flexibility: a comparison between two techniques. Am J Sports Med 1985;13:263-8.

29 Taylor DC, Dalton JD, Seaber AV, et al. Viscoelastic properties of muscletendon units: the biomechanical effects of stretching. Am J sports Med 1990; 18:300-9.

30 Bandy WD, Irion JM. The effect of time of static stretch on the flexibility of hamstring muscles. Phys Ther 1994:74:845-52.

31 Grady JF, Saxena A. Effects of stretching the gastrocnemius muscle. J Foot Surg 1991;30:465-9.

32 Stanton P, Purdam C. Hamstring injuries in sprinting-the role of eccentric exercise. Physiotherapy in Sport 1995;18:6-11.

33 Sullivan MK, Dejulia JJ, Worrell TW. Effect of pelvic position and stretching method on hamstring muscle flexibility. Med Sci Sports Exerc 1992;24:1383-9

34 Eales M. Physical profiling in English professional football and its use to guide return to unrestricted training following injury. Unpublished MSc Sports Medicine Thesis, Centre for Sports Medicine, University of Nottingham, 1999.

35 Gibbs N. Injuries in professional league: a three year prospective study of the South Sydney professional rugby league football club. Am J Sports Med 1993;21:696-700.

36 Knott M, Voss DE. Proprioceptive neuromuscular facilitation. New York: Harper and Row, 1968.

37 Football Association. National course programme. London: The Football Association, 1999.

38 Laurenson N. Warm-up and stretching. In: Hackney RG, Wallace WA, eds. Sports medicine handbook. London: BMJ, 1999:17-53.

39 Roberts JM, Wilson K. Effect of stretching duration on active and passive range of motion in the lower extremity. Br J Sports Med 1999;33:259-63.

40 Ekstrand J, Gullquist J, Lilzedahl S-S. Prevention of soccer injuries. Supervision by doctor and physiotherapist. Am J Sports Med 1983;11:116-20.

41 Garrett WE Jr, Rich FR, Nikolaou PK, et al. Computed tomography of hamstring strains. Med Sci Sports Exerc 1989;21:506.

42 Best TM, Garrett WE. Hamstring strains: expediting return to play. Phys Sportsmed 1996;24:37

43 Bangsbo J, Norregaard L, Thorsoe F. Activity profiles of competitive soccer Can J Sport Sci 1991;16:110-16.

44 Reilly T. The physical demands of football. Insight 1997;1:17-21.

45 Oberg B, Ekstrand J, Moller M, et al. Muscle strength and flexibility in different positions of soccer players. Int J Sports Med 1984;5:213-16.

46 Orchard J, Marsden J, Lord S, et al. Preseason hamstring muscle weakness associated with hamstring muscle injury in Australian footballers. Am J Sports Med 1997; 25:81-5

47 Agre JC. Hamstring injuries. Proposed aetiological factors, prevention and treatment. Sports Med 1985;2:21. 


\section{PostScript}

\section{LETTER}

If you have a burning desire to respond to a paper published in Br J Sports Med, why not make use of our "rapid response" option?

Log on to our website (www.bjsportmed. com), find the paper that interests you, click on "full text" and send your response by email by clicking on "eletters" submit a response.

Providing it isn't libellous or obscene, it will be posted within seven days. You can retrieve it by clicking on "read eletters" on our homepage.

\section{Sodium ingestion and the prevention of hyponatraemia during exercise}

The study of Twerenbold et $a l^{1}$ is important for a number of reasons, not all of which may have been emphasised sufficiently by the authors.

Firstly, it confirms that a rate of fluid intake of $1000 \mathrm{ml} / \mathrm{h}$ is too high for a group of female runners running at $\sim 10 \mathrm{~km} / \mathrm{h}$ and who would therefore complete a $42 \mathrm{~km}$ marathon in about 4.25 hours. As the athletes drank 4 litres and gained $2 \mathrm{~kg}$ during the trial, their average rate of weight loss (as opposed to sweat rate) was about $500 \mathrm{ml} / \mathrm{h}$. As not all of the weight lost during exercise is sweat and as much as $1-3 \mathrm{~kg}$ of this weight loss may result from fuel and water losses that do not contribute to dehydration, ${ }^{23}$ the absolute maximum rate at which these athletes should have ingested fluid during exercise was probably even less than $500 \mathrm{ml} / \mathrm{h}$. This is substantially less than the drinking guidelines of the American College of Sports Medicine $^{45}$ and the Gatorade Sports Science Institute, ${ }^{6}$ which have promoted rates of fluid ingestion of up to $1200-1800 \mathrm{ml} / \mathrm{h}$. As there is no evidence that gaining weight during exercise improves performance ${ }^{78}$ whereas there is good evidence that athletes who either lose no weight or who gain weight during exercise are increasingly likely to $(a)$ have an impaired performance, ${ }^{7}(b)$ develop troubling gastrointestinal symptoms, ${ }^{7-10}$ or $(c)$ finish the race with serum sodium concentrations below about $128 \mathrm{mmol} / \mathrm{l}$ causing hyponatraemic encephalopathy, ${ }^{11-13}$ it is not immediately clear why the authors chose such high rates of fluid intake in these athletes. Except, perhaps, if they wished to "prove" the value of sodium ingestion during exercise. I note, for example, that the study was funded by a commercial company that, I am informed, markets a sports drink containing sodium chloride.

For it seems highly probable that if athletes overdrink so that they retain fluid and gain weight, then the extent to which their serum sodium concentration falls will be influenced, albeit to a quite limited extent, by the sodium content of the ingested fluids. This indeed was shown by the results of this study. But whether that finding has relevance to the sodium requirements of athletes who are specifically advised not to overdrink during exercise to ensure that they do not develop hyponatraemic encephalopathy ${ }^{13}$ is an entirely different question, which cannot be answered with the study design chosen by these authors.

For example, the presence of a control group who drank according to the dictates of thirst ("ad libitum") and not according to the guidelines of influential sports medical ${ }^{45}$ and

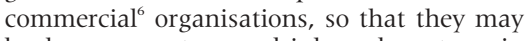
be less prone to overdrink and so to gain weight during exercise, would have established that athletes who lose more than 1-3 kg during exercise do not develop symptomatic hyponatraemic encephalopathy ${ }^{11-16}$ even though they are both dehydrated and sodium deficient. Rather, they are more likely to finish such races with raised serum sodium concentrations. ${ }^{12-16}$

I would rather argue that a fundamental feature of all prospective trials that aim to evaluate a novel intervention such as the role of sodium ingestion in the prevention of hyponatraemia during exercise should be to compare the new intervention with the currently established "best practice".

As the currently established best practice is not to ingest fluid at such high rates that weight is gained during exercise, because this practice can produce a fatal outcome, ${ }^{17}$ so this study design should, in retrospect, not have been sanctioned. Rather, the control group in the study should have ingested fluid according to guidelines based on the strongest body of current information. It is, for obvious reasons, my biased opinion that the guidelines that come closest to a defendable evidence base are those that have been recently accepted by the United States Track and Field and the International Marathon Medical Directors Association. ${ }^{16}$

Fortunately the data of Twerenbold et al ${ }^{1}$ do allow some calculations to estimate the likely value of the extra sodium that was ingested by two of their groups. Thus, the athletes in their study had a mean weight of $58 \mathrm{~kg}$. According to the formula of Montain et al, ${ }^{18}$ their predicted extracellular fluid (ECF) volume would be about 14.5 litres $(25 \%$ of body weight). As the starting serum (and ECF) sodium concentration $\left(\left[\mathrm{Na}^{+}\right]\right)$in the three groups of runners was $\sim 137 \mathrm{mmol} / \mathrm{l}$ (table 3 of their article ${ }^{1}$ ), the average total ECF $\mathrm{Na}^{+}$content of the three experimental groups was 1989-1993 mmol at the start of the race. As weights increased by $1.8-2.1 \mathrm{~kg}$ in the three groups during exercise (table 3 of their article ${ }^{1}$ ), the increases in ECF volume would have been $450-525 \mathrm{ml}$ in the respective groups, assuming that the ECF increased in proportion to the increase in total body water (TBW). Multiplying this new ECF volume by the serum $\left[\mathrm{Na}^{+}\right]$after the race gives the new total ECF $\mathrm{Na}^{+}$content after the race. As shown in table 1 , the total ECF $\mathrm{Na}^{+}$ content increased by $34 \mathrm{mmol}$ in the group that ingested the high salt drink $(\mathrm{H})$ during the race, but fell by $23 \mathrm{mmol}$ in the group drinking water (W). As all groups ran for about four hours, according to these calculations and based on these assumptions, the hourly rates of $\mathrm{Na}^{+}$loss would have varied from 6 to $21 \mathrm{mmol} / \mathrm{h}$, giving a sweat $\left[\mathrm{Na}^{+}\right]$of $12-42 \mathrm{mmol} / \mathrm{l}$ in the $\mathrm{W}$ and $\mathrm{H}$ groups respectively (as their total sweat losses were $\sim 2$ litres in each group).

The clear paradox identified by the calculations in table 1 is that $(a)$ the total $\mathrm{Na}^{+}$loss apparently increases with increased $\mathrm{Na}^{+}$ intake and $(b)$ the estimated $\mathrm{Na}^{+}$loss in the group who ingested only water during the race $(\mathrm{W})$ is less than one third of that in the group who ingested the most $\mathrm{Na}^{+}(\mathrm{H})$ during the race.

As these calculations are based on two real measurements (body weight changes and changes in plasma $\left.\left[\mathrm{Na}^{+}\right]\right)$, this apparently ludicrous conclusion can only be explained if (a) $\mathrm{Na}^{+}$ingestion during exercise increases whole body $\mathrm{Na}^{+}$losses in sweat and urine or (b) the estimated ECF volume in the W group after exercise is less than the value calculated. That is, specifically in the $\mathrm{W}$ group, the ECF volume contracted despite an increase in TBW of 1.9 litres. Indeed, this response is to be expected. There is consistent evidence that the response of the ECF and the intracellular fluid (ICF) volumes to fluid ingestion during prolonged exercise are influenced by the $\mathrm{Na}^{+}$ content of the ingested fluid ${ }^{19-21}$ so that the plasma volume is likely to fall the most if no fluid is ingested, ${ }^{19}$ to fall less if either water ${ }^{19}$ or a dilute $\mathrm{Na}^{+}$drink is ingested, ${ }^{19-21}$ or to expand if a concentrated (50-100 mmol/l) $\mathrm{Na}^{+}$drink is ingested at the same rate that body weight is lost during exercise. ${ }^{20}$ In the latter case, any reduction in the TBW appears to come from a reduction in the ICF. ${ }^{20}$

For example, if each group did indeed lose $84 \mathrm{mmol} \mathrm{Na}^{+}$as did group $\mathrm{H}$ (table $\mathrm{l}$ ), a value that seems eminently reasonable as it equates to a quite reasonable sweat $\left[\mathrm{Na}^{+}\right]$of $\sim 40 \mathrm{mmol} / \mathrm{l},{ }^{22}$ then the true ECF volume in the $\mathrm{W}$ group after the race would have been 14.5 litres-that is, it is unchanged from the starting value. This value (expressed in litres) is calculated as: (pre-race ECF $\mathrm{Na}^{+}$content 84 ) in mmol divided by post-race serum $\left[\mathrm{Na}^{+}\right]$in $\mathrm{mmol} / \mathrm{l}$.

Indeed, if subjects in the $\mathrm{W}$ group did lose $84 \mathrm{mmol} \mathrm{Na}^{+}$during the race but also had a post-race ECF volume expanded to 14.95 litres, then their post-race $\left[\mathrm{Na}^{+}\right]$would have been even lower $(128 \mathrm{mmol} / \mathrm{l})$ than that actually measured after the race $(132 \mathrm{mmol} / \mathrm{l}$; table 1). It is probable that, at that low serum $\left[\mathrm{Na}^{+}\right]$, they would have exhibited the early symptoms of hyponatraemic encephalopathy. ${ }^{11}$ That they did not have such low serum $\left[\mathrm{Na}^{+}\right]$indicates the importance of small changes in ECF volume (in this case only $450 \mathrm{ml}$ or $\sim 3 \%$ of the total ECF volume) in determining the extent to which the serum $\left[\mathrm{Na}^{+}\right]$changes during prolonged exercise in which subjects both sweat and ingest fluid to excess. ${ }^{11}$

Unfortunately, the vital importance of these small changes in ECF volume in determining whether hyponatraemic encephalopathy will develop in those who overdrink during exercise ${ }^{11}$ continues fastidiously to be ignored by those $e^{1-61823-25}$ who argue incorrectly that it is the $\mathrm{Na}^{+}$deficit that determines the extent to which the serum $\left[\mathrm{Na}^{+}\right]$ falls in those who develop hyponatraemia during exercise. This calculation elegantly shows why small changes in ECF volume determine whether or not hyponatraemic 
Table 1 Sodium balance calculations for three groups of runners running at $\sim 10 \mathrm{~km} / \mathrm{h}$ for four hours while ingesting solutions with different $\left[\mathrm{Na}^{+}\right]$

\begin{tabular}{|c|c|c|c|c|c|c|c|c|c|}
\hline & $\begin{array}{l}\text { Pre-race } \\
{\left[\mathrm{Na}^{+}\right]} \\
(\mathrm{mmol} / \mathrm{I})(\mathrm{A})\end{array}$ & $\begin{array}{l}\text { Pre-race } \\
\text { ECF volume } \\
\text { (litres) (B) }\end{array}$ & $\begin{array}{l}\text { Pre-race ECF } \\
\mathrm{Na}^{+} \text {content } \\
(\mathrm{mmol})(\mathrm{A} \times \mathrm{B})\end{array}$ & $\begin{array}{l}\text { Post-race }\left[\mathrm{Na}^{+}\right] \\
(\mathrm{mmol} / \mathrm{ll})(\mathrm{C})\end{array}$ & $\begin{array}{l}\text { Post-race } \\
\text { ECF volume } \\
\text { (litres) (D) }\end{array}$ & $\begin{array}{l}\text { Post-race ECF } \\
\mathrm{Na}^{+} \text {content } \\
(\mathrm{mmol})(\mathrm{C} \times \mathrm{D})\end{array}$ & $\begin{array}{l}\text { Post-race } \mathrm{Na}^{+} \\
\text {balance }(\mathrm{mmol})(\mathrm{E}) \\
(\mathrm{C} \times \mathrm{D})-(\mathrm{A} \times \mathrm{B})\end{array}$ & $\begin{array}{l}\text { Amount of } \\
\mathrm{Na}^{+} \text {ingested } \\
\text { (mmol) (F) }\end{array}$ & $\begin{array}{l}\text { Apparent amount } \\
(\mathrm{mmol}) / \text { rate } \\
\text { of } \mathrm{Na}^{+} \text {loss during } \\
\text { exercise (mmol/h) } \\
((\mathrm{F}-\mathrm{E}) / 4)\end{array}$ \\
\hline $\mathrm{H}$ & 137.3 & $14.50^{*}$ & 1991 & 134.8 & 15.02 & 2025 & +34 & $118 \dagger$ & $84 / 21$ \\
\hline L & 137.2 & 14.50 & 1989 & 132.8 & 14.95 & 1985 & -4 & 71 & $76 / 19$ \\
\hline W & 137.5 & 14.50 & 1993 & 131.8 & 14.95 & 1970 & -23 & 0 & $24 / 6$ \\
\hline
\end{tabular}

$\mathrm{H}$, High sodium intake; $\mathrm{L}$, low sodium intake; $\mathrm{W}$, water during exercise.

*Based on $25 \%$ of mean body weight of $57.7 \mathrm{~kg}$ for the total group of runners. Weights for different groups were not reported.

†From table 2 of Twerenbold et al': to convert $\mathrm{mg}$ sodium (table 2) into mmol sodium, divide by the molecular weight of sodium (22.99).

encephalopathy will develop in those who overdrink, regardless of whether or not they also incur a $\mathrm{Na}^{+}$deficit either during exercise $^{311-13152627}$ or at rest. ${ }^{229}$ A recent paper ${ }^{30}$ confirms these predictions by showing that mathematical modelling supports the argument that changes in TBW exert a much greater effect on serum $\left[\mathrm{Na}^{+}\right]$than does whole body $\mathrm{Na}^{+}$content in those who overdrink and hence gain weight during exercise.

Perhaps the point of these calculations is to show that it is not possible to calculate the state of $\mathrm{Na}^{+}$balance in athletes during exercise and so to determine whether or not athletes have developed a $\mathrm{Na}^{+}$"deficit", ${ }^{1623-25}$ simply by measuring serum $\left[\mathrm{Na}^{+}\right]$. This is because the ECF volume will not be the same before, during, and after exercise and will change depending on the nature of the fluid ingested and the extent of any fluid deficit or excess that develops during exercise..$^{19-21}$

But more importantly, these calculations clearly show why the regulation of the TBW and the ECF volume will have a much greater influence on serum $\left[\mathrm{Na}^{+}\right]$than will either the expected $\mathrm{Na}^{+}$losses in sweat or the amount of $\mathrm{Na}^{+}$ingested from sodium-containing sports drinks. ${ }^{11}{ }^{30}$

For example a 1 litre $(7 \%)$ reduction in the ECF volume would "release" $140 \mathrm{mmol} \mathrm{Na}{ }^{+}$ into the contracted ECF volume. This means that it is possible to lose $140 \mathrm{mmol} \mathrm{Na}{ }^{+}$in sweat and urine without any change in serum $\left[\mathrm{Na}^{+}\right]$provided that the ECF volume were to contract by only $7 \%$. If sweat $\left[\mathrm{Na}^{+}\right]$is about $40 \mathrm{mmol} / \mathrm{l}$, as appears to have been the case in this study of Twerenbold et al (table 1), then this $140 \mathrm{mmol}$ is the equivalent of the $\mathrm{Na}^{+}$content of about 3.5 litres of sweat.

As athletes in this study sweated at a maximum rate of only $500 \mathrm{ml} / \mathrm{h}$ when running at $10 \mathrm{~km} / \mathrm{h}$, this means that simply by reducing their ECF volume by 1 litre, those athletes could have maintained their pre-race serum $\left[\mathrm{Na}^{+}\right]$while running for seven hours and drinking just sufficient water to allow for a 1 litre reduction in ECF volume and without requiring any $\mathrm{Na}^{+}$replacement whatsoever. This simple calculation explains why those endurances athletes who, before about 1969, were advised either not to drink at all, or only sparingly during exercise, ${ }^{31}$ always finished their races with raised serum $\left[\mathrm{Na}^{+}\right]^{32-39}$ despite having incurred what might have been quite sizeable $\mathrm{Na}^{+}$deficits.

In contrast, athletes in this study who believed the incorrect advice that ingesting $\mathrm{Na}^{+}$and fluid at high rates is essential to maintain a normal serum $\left[\mathrm{Na}^{+}\right]$during exercise, ${ }^{4-61823-25}$ so they overdrank sufficiently to increase their ECF volume by
1 litre, would need to ingest and retain at least an additional $140 \mathrm{mmol} \mathrm{Na}^{+}$in addition to the $\sim 80 \mathrm{mmol}$ lost in sweat (table 1). This is equivalent to the $\mathrm{Na}^{+}$content of 12.4 litres of the low and 7.5 litres of the high sodium drinks respectively in this trial. To maintain fluid balance in this four hour trial when drinking at those high rates and sweating at about $500 \mathrm{ml} / \mathrm{h}$, they would then need to urinate at rates of $1375-2600 \mathrm{ml} / \mathrm{h}$. Both of these rates exceed the maximum at which human kidneys are able to produce urine at rest, ${ }^{28} 29$ let alone during and after prolonged exercise. ${ }^{11}{ }^{13}$ Drinking at such rates would therefore only lead to progressive fluid accumulation and ultimately death from hyponatraemic encephalopathy. ${ }^{17}$

In summary, these calculations explain (a) why contraction of the ECF in athletes who lose body weight during exercise will maintain the serum $\left[\mathrm{Na}^{+}\right]$even in the face of quite large and unreplaced $\mathrm{Na}^{+}$loss in sweat, and (b) why the ingestion of sodium-containing sports drinks in the vain hope of matching the rates of $\mathrm{Na}^{+}$loss in sweat can only lead to fluid retention and progressive hyponatraemia, as elegantly shown by this study.' Indeed if this inappropriate behaviour is approached with sufficient vigour, ultimately the result will be death from hyponatraemic encephalopathy, ${ }^{17}$ which, as these calculations and this study again show, cannot occur without the presence of distinct fluid overload. ${ }^{11}$

Finally, it is important to note that, even though $\mathrm{Na}^{+}$ingestion marginally increased serum $\left[\mathrm{Na}^{+}\right]$in the group that ingested the most concentrated $\mathrm{Na}^{+}$drink, this practice was without benefit as running performances were unaltered by $\mathrm{Na}^{+}$ingestion, and the incidence of symptoms was no different between the groups as no athletes reportedly developed symptoms. However, the symptoms of mild hyponatraemic encephalopathy are mild and may not have been sought with sufficient diligence. For example, all subjects, myself included, in our study in which mild hyponatraemia was induced by fluid overload at rest, ${ }^{28}$ developed quite disabling symptoms at serum $\left[\mathrm{Na}^{+}\right]$of $\sim 136 \mathrm{mmol} / \mathrm{l}$ or lower. Indeed it would have been most interesting to determine whether the presence of subtle mental symptoms was different in the three groups in this study, as all had similar degrees of fluid overload despite different serum $\left[\mathrm{Na}^{+}\right]$. If the symptoms in this condition are due purely to fluid overload, then the incidence of symptoms should have been the same in all groups despite different serum $\left[\mathrm{Na}^{+}\right]$. Alternatively, if the symptoms are related to the degree of hyponatraemia, then they should have been most obvious in the $\mathrm{W}$ group, who finished with the lowest postrace serum $\left[\mathrm{Na}^{+}\right]$. My bias would be to expect that the extent of any symptoms are more likely related to the degree of fluid overload, and hence the increase in the ICF, than to the level to which the serum $\left[\mathrm{Na}^{+}\right]$has been reduced.

T Noakes

Correspondence to: University of Cape Town, Research Unit for Exercise Science and Sports Medicine, Sports Science of South Africa, PO Box

115, Newlands 7725, South Africa; tdnoakes@ sports.uct.ac.za

doi: 10.1136/bjsm.2004.014191

Conflict of interest: none declared

\section{References}

1 Twerenbold R, Knechtle B, Kakebeeke TH, et al. Effects of different sodium concentrations in replacement fluids during prolonged exercise in women. Br J Sports Med 2003;37:300-3

2 Pastene J, Germain M, Allevard AM, et al. Water balance during and after marathon running. Eur J Appl Physiol Occup Physiol 1996;73:49-55

3 Speedy DB, Noakes TD, Kimber NE, et al. Fluid balance during and after an ironman triathlon. Clin J Sport Med 2001;11:44-50.

4 Convertino VA, Armstrong LE, Coyle EF, et al. American College of Sports Medicine position stand. Exercise and fluid replacement. Med Sci Sports Exerc 1996;28:i-vii.

5 Armstrong LE, Epstein YE, Greenleaf JE, et al. Position stand: heat and cold illnesses during distance running. Med Sci Sports Exerc 1996;28:i-x

6 Murray B. How often should you drink fluids? Gatorade Sports Science Institute Sports Science Centre. 2002. http://www.gssiweb.com/reflib/ refs/419/200104_q1.cfm?pid = 38 .

7 Robinson TA, Hawley JA, Palmer GS, et al. Water ingestion does not improve 1-h cycling performance in moderate ambient temperatures Eur J Appl Physiol Occup Physiol 1995;71:153-60.

8 Noakes TD. Letter to the Editor. Int J Sport Nutr Exerc Metab 2004; 14:249-54.

9 Glace B, Murphy C, McHugh M. Food and fluid intake and disturbances in gastrointestinal and mental function during an ultramarathon. Int J Sport Nutr Exerc Metab 2002:12:414-27.

10 Glace BW, Murphy CA, McHugh MP. Food intake and electrolyte status of ultramarathoners competing in extreme heat. $J \mathrm{Am}$ Coll Nutr 2002;21:553-9.

11 Noakes T. Hyponatremia in distance runners: fluid and sodium balance during exercise. Curr Sports Med Rep 2002;1:197-207.

12 Speedy DB, Noakes TD, Rogers IR, et al. Hyponatremia in ultradistance triathletes. Med Sci Sports Exerc 1999:31:809-15.

13 Noakes TD, Sharwood K, Collins M, et al. The dipsomania of great distance. Water intoxication 
in an Ironman triathlete $\mathrm{Br} J$ Sports Med 2004;38:el6.

14 Sharwood K, Collins M, Goedecke J, et al. Weight changes, medical complications and performance during an Ironman triathlon. Br J Sports Med 2004; in press.

15 Speedy DB, Rogers IR, Noakes TD, et al. Diagnosis and prevention of hyponatremia at an ultradistance triathlon. Clin J Sport Med $2000 \cdot 10 \cdot 52-8$

16 Noakes TD. Fluid Replacement during Marathon Running. Clin J Sport Med 2003;13:309-18.

17 Noakes TD. Overconsumption of fluids by athletes. BMJ 2003;327:113-14.

18 Montain SJ, Sawka MN, Wenger CB. Hyponatremia associated with exercise: risk factors and pathogenesis. Exerc Sport Sci Rev 2001;29:113-17.

19 Sanders B, Noakes TD, Dennis SC. Water and electrolyte shifts with partial fluid replacement during exercise. Eur $J$ Appl Physiol Occup Physiol 1999;80:318-23.

20 Sanders B, Noakes TD, Dennis SC. Sodium replacement and fluid shifts during prolonged exercise in humans. Eur J Appl Physiol 2001;84:419-25.

21 Speedy DB, Thompson JM, Rodgers I, et al. Oral salt supplementation during ultradistance exercise. Clin J Sport Med 2002;12:279-84

22 Shirreffs SM, Maughan RJ. Whole body sweat collection in humans: an improved method with preliminary data on electrolyte content. $J$ Appl Physiol 1997:82:336-41.

23 Armstrong LE. Exertional hyponatremia. In: Armstrong LE, ed. Exertional heat illnesses. Champaign, IL: Human Kinetics Publishers, 2003:103-35.

24 Murray B, Eichner ER. Hyponatremia of exercise. Curr Sports Med Rep 2004;3:117-18.

25 Murray B, Stofan J, Eichner ER. "Water intoxication" and subsequent death has become a "hot" topic. How dangerous is it? Marathon \& Beyond 2004 Jan/Feb:77-92.

26 Irving RA, Noakes TD, Buck R, et al. Evaluation of renal function and fluid homeostasis during recovery from exercise-induced hyponatremia. J Appl Physiol 1991;70:342-8.

27 Speedy DB, Rogers IR, Noakes TD, et al. Exercise-induced hyponatremia is caused by inappropriate fluid retention. Clin J Sport Med 2000;10:272-8.

28 Noakes TD, Wilson G, Gray DA, et al. Peak rates of diuresis in healthy humans during oral fluid overload. S Afr Med J 2001;91:852-7.

29 Speedy DB, Noakes TD, Boswell T, et al Response to a fluid load in athletes with a history of exercise induced hyponatremia. Med Sci Sports Exerc 2001;33:1434-42.

30 Weschler LB. Exercise-associated hyponatremia: sensitivity of plasma $\mathrm{Na}^{+}$concentration to total body water, change in total body water and sum of exchangeable $\mathrm{Na}^{+}$and $\mathrm{K}^{+}$. Sports Med 2004; in press.

31 Noakes TD. Fluid replacement during exercise Exerc Sport Sci Rev 1993;21:297-330.

32 Beckner GL, Winsor T. Cardiovascular adaptations to prolonged effort. Circulation 1954;9:835-46

33 Pugh LGCE, Corbett JL, Johnson RH. Rectal temperatures, weight losses, and sweat rates in marathon running. J Appl Physio 1967;23:347-52.

34 Muir AL, Percy-Robb IW, Davidson IA, et al. Physiological aspects of the Edinburgh Commonwealth Games. Lancet 1970;2:1125-8.

35 Rose LI, Carroll DR, Lowe SL, et al. Serum electrolyte changes after marathon running. J Appl Physiol 1970;29:449-51.

36 Kavanagh T, Shephard RJ. Marathon running after myocardial infarction. JAMA 1974;229:1602-5.

37 Riley WJ, Pyke FS, Roberts AD, et al. The effects of long-distance running on some biochemical variables. Clin Chim Acta 1975;65:83-9

38 Noakes TD, Carter JW. Biochemical parameters in athletes before and after having run $160 \mathrm{~km}$. S Afr Med J 1976;50:1562-6.

39 McKechnie JK, Leary WP, Noakes TD. Metabolic responses to a $90 \mathrm{~km}$ running race. S Afr Med J 1982;61:482-4.

\section{BOOK REVIEWS}

\section{Tennis}

Edited by P A F H Renstrom. London: Blackwell Publishing, 2002, £29.95, pp 318, softcover. ISBN 0632050349

It is widely recognised that each sport has its own unique demands and injuries. Therefore the IOC, ITF, ATP, WTA, and Society for Tennis Medicine and Science should be congratulated on producing, in this publication, a comprehensive overview of tennis sports medicine. Together they have assembled an impressive array of experts in this field to write succinct and relevant chapters.

Every aspect of tennis is covered to cater for a broad range of readers, including players themselves. Some areas are covered in a high level of technical detail to please the biomechanists, in particular. However, some of the sports medicine is basic in concept and lacking significant evidence based validity.

Nevertheless, I would highly recommend this book to any health professional who treats a large number of tennis players. Most chapters provide a clever link between common sports medicine problems and their occurrence in tennis, including conditions that are unique to this sport. At times, some authors are somewhat optimistic with their view of recovery time from surgery-for example, three weeks for arthroscopic debridement of the infrapatellar fat pad.

Overall it is well presented with relevant and useful photographs and diagrams to aid the reader, and each chapter gives a list of further recommended reading. Unfortunately the book does not provide an answer to where 14 million tennis balls go, imported each year into Australia, as discussed by the editor recently!

\section{Rating}

- Presentation

- Comprehensiveness

- Readability

- Relevance

- Evidence basis

- Total $16 / 20$

$15 / 20$

$15 / 20$

$16 / 20$

$13 / 20$

$75 / 100$
T Wood

\section{Dying to win}

Edited by B Houlihan. Council of Europe Publishing, 2002, £17.95, softcover, pp 247. ISBN 9287146853

Dying to win gives an eye opening account of the extent to which drugs play a major role in sport. Doping is not new and has been used in sport since ancient Olympic times; it is just that drug use in modern times is at such a level of sophistication, it is now an industry in its own right. The book describes the privileged position sport holds in society, having appeal for both the participant and the spectator. This has led to the massive media interest, commercialism, professionalism, and governmental regulation and manipulation. Economic pressure in the industrialised world and governmental propaganda in the former East Germany, and more recently China, paved the way for the increasing pharmaceutical intervention in sport. With the fall of the GDR, the world saw for the first time what it had long suspected, the extent of systematic doping on a State run basis, and the most interesting fact is that the East Germans kept excellent records! Further, the book takes a look at the next big issue surrounding drugs in sportgenetic engineering.

Dying to win does not just describe the evolution of doping. It explains the complex relation between anti-doping policy, implementation of those policies, and the role of governments, the IOC, and international and national sporting organisations. With the ever increasing involvement of the legal profession, a vicious circle occurs: it becomes too costly for sporting organisations to fight court battles, with their reliance on Government funding depending on results and punishments set in accordance with what will stand up in courts. This all leads to the relative inertia of the governing bodies to be pro-active in the anti-drugs campaign. The inception of the World Anti-Doping Agency (WADA) after the 1998 Tour de France drugs fiasco provided a way forward to standardise and implement anti-doping policy across the world by an independent body.

Problems and solutions to anti-doping policy are addressed. The major problem is inadequate definition of doping - to quote Arthur Gold "The definition lies not in words but in integrity of character.". It is interesting to note that those behind the athlete, namely coach, administrators, medical profession, and scientists, all seem to lose perspective along with their ethics and "integrity of character" when the race for "gold" is on. Dying to win suggests that these people should be held just as accountable as the athletes themselves. Another unfortunate aspect of anti-doping policy is the difficulty in detecting some abused drugs and the fact that these strategies often lag way behind the ability of the pharmaceutical industry to develop new drugs, often for genuine medical reasons but with the unfortunate ability to enhance performance. Education is proposed as a key aspect to anti-doping policy, and parallels with its success in the use of recreational drugs are made. Governments also play a role in limiting supply, decreasing demand for drugs, and the implementation of independent bodies to carry out drug testing. The success of anti-doping policy is also hard to measure. Fewer positive tests may simply reflect a move to less detectable methods rather than a decrease in use, and success may be better measured in terms of fewer world records.

Dying to win gives an accurate account of the problem of doping in sport and the difficulties and complexities in finding solutions to the problems. It makes interesting and provocative reading for all those involved in sport, from the athlete and coach to the sport administrator, the medical profession, and governments. 


\section{Rating}

- Presentation

- Comprehensiveness

- Readability

- Relevance

- Evidence basis

- Total

$17 / 20$

$19 / 20$

$15 / 20$

$18 / 20$

$19 / 20$

$88 / 100$

E Clisby

Chair Drugs in Sport, Sports Medicine Australia; eclisby@healthon-net.com

\section{CALENDAR OF EVENTS}

\section{UK Radiological Congress 2005 (UKRC 2005)}

6-8 June 2005, Manchester, UK

The UK Radiological Congress (UKRC) meeting will encompass the medical, scientific, educational, and management issues that are of interest and relevance to all those involved in the diverse fields of radiological sciences and oncology.

The UKRC provides a forum in which to bring together clinicians, scientists, radiographers, technicians, and other professionals to present and discuss the latest developments and challenges in diagnostic imaging, radiotherapy, and allied radiological sciences.

Key subjects to be covered include: diagnostic radiology; ultrasound; nuclear medicine; interventional radiology; veterinary radiology; emerging technologies; image analysis; computer applications; PACS; radiobiology; radiological physics; management \& audit; computed tomography; magnetic resonance; equipment development.

Expected attendance (conference and exhibition): 4000

Further details: UKRC 2005 Organisers, PO Box 2895, London WIA 5RS, UK; Website: www.ukrc.org.uk; Fax: +44 (0)20 7307 1414; Conference tel: +44 (0)20 7307 1410, Email: conference@ukrc.org.uk; Exhibition tel: +44 (0)207307 1420, Email: exhibition@ukrc. org.uk

\section{1st World Congress on Sports Injury} Prevention

23-25 June 2005, Oslo, Norway

This congress will provide the world's leading sports medicine experts with an opportunity to present their work to an international audience made up of physicians, therapists, scientists, and coaches. The congress will present scientific information on sports injury epidemiology, risk factors, injury mechanisms and injury prevention methods with a multidisciplinary perspective. Panel discussions will conclude symposia in key areas providing recommendations to address the prevention issue in relation to particular injuries and sports.

Further details: Oslo Sports Trauma Research Centre and Department of Sports Medicine, University of Sport and Physical Education, Sognsveien 220, 0806 Oslo, Norway. Email: 2005congress@nih.no; website: www.ostrc.no

\section{Osteosynthese International 2005}

15-17 September 2005, Curiohaus, Hamburg Congress-Chairman: Johannes M. Rueger,

M.D., Professor and Chair Topics:

- Innovations in intramedullary osteosynthesis

- New frontiers in osteoporosis and fracture treatment

- Current trauma research

- Special topic: Recent development in pelvic and acetabular fractures

Abstract submission deadline: 31 March 2005

Further details: INTERCONGRESS GmbH, Martin Berndt, Düsseldorfer Str. 101, 40545 Düsseldorf-Germany. Tel: +49 $211585897-$ 80; fax: +49 211 585897-99; email: martin. berndt@intercongress.de; website: www. osteoint2005.de

\section{4th European Sports Medicine Congress}

13-15 October 2005, Lemesos, Cyprus

Further details: Email: pyrgos.com@cytanet. com.cy

\section{BASEM Conference 2005}

10-12 November 2005, Edinburgh, Scotland Further details: Email: basemoffice@ compuserve.com
BASEM Conference 2006

5-7 October 2006, Oxford, UK

Further details: Email: basemoffice $a$ compuserve.com

\section{CORRECTIONS}

doi: 10.1136/bjsm.2004.00392 1corr l

Cicharro J L, Hoyos J, Gómez-Gallego F, et al. Mutations in the hereditary haemochromatosis gene HFE in professional endurance athletes (Br J Sports Med 2004;38:418-21). The affiliation of $\mathrm{P}$ Celaya was published incorrectly. The correct affiliation is Professional Cycling Team US Postal-Berry Floor. We apologise for this error.

doi: 10.1136/bjsm.2004.000044corr 1

Dadebo B, White J, George K P. A survey of flexibility training protocols and hamstring strains in professional football clubs in England (Br J Sports Med 2004;38:388-94). The multiple regression equation within the Abstract section of this paper was published incorrectly. The correct equation is:

$\mathrm{HSR}=37.79-(0.33 \mathrm{SHT}+10.05 \mathrm{SSP}+2.24 \mathrm{STE})$ $\pm 2.34$

We apologise for this error.

doi: 10.1136/bjsm.2004.010876corr l

Sran M M. To treat or not to treat: new evidence for the effectiveness of manual therapy (Br J Sports Med 2004;38:521-5).

The volume number for reference 23 (Sran et al) was incorrectly published as 24; the correct volume number is 29 .

In Table 2 the results for Giles and Muller should read: Greater short term benefit for back pain with manipulation, but not for neck pain. Acupuncture more effective for neck pain.

In the section "Definitions and search strategy" the first line of paragraph 2 should read: I searched Medline, Cinahl, and Embase databases for randomised clinical trials comparing manual therapy, including spinal joint mobilisation (with or without manipulation) or manipulation only with other conservative treatments for back or neck pain.

We apologise for these errors. 